\title{
SHAPE OPTIMIZATION OF A COLUMN UNDER GENERALIZED LOAD WITH A FORCE DIRECTED TOWARDS POSITIVE POLE
}

doi: 10.2478/cqpi-2019-0044

Date of submission of the article to the Editor: 25/03/2019

Date of acceptance of the article by the Editor: 24/05/2019

Janusz Szmidla ${ }^{1}$ - orcid id: 0000-0002-7475-7925
Anna Jurczyńska ${ }^{1}$ - orcid id: 0000-0002-8505-3157
${ }^{1}$ Częstochowa University of Technology, Poland

Abstract: In this paper, the issue of shape optimization of a column subjected to the generalized load with a force directed towards the positive pole (L. Tomski's load, specific load) was considered. Based on the Hamilton's principle, the differential equations of movement and boundary conditions describing the system were formulated. Taking into account a kinetic criterion of stability loss and a condition of constant total volume, the scope of changes in natural frequency as a function of an external load was determined with selected geometrical and physical parameters of the loading structure. On the basis of obtained results, values of geometrical parameters of individual column segments were determined, at which the maximum critical load value was obtained. In order to find the maximum critical force, which is a function of many variables, the simulated annealing algorithm was used.

Keywords: shape optimization, stability, free vibrations

\section{INTRODUCTION}

The stability of the columns depends not only on the load type of the system or its support, but also on the cross-section and the change of this cross-section along the length of the column. In the case of constant efforts to minimize the weight of mechanical systems and maximize their strength, of great importance is the issue of optimization of such systems. Shape optimization issues can be found, among others in the works of Drazumeric and Kosel, 2012, Ruta and Szybiński, 2015, Tsiatas, 2010, Krużelecki and Barski, 2008, Bochenek and Tajs-Zielińska, 2008, Nikolic and Salinic, 2017, Szmidla and Jurczyńska, 2015 and Szmidla and Wawszczak, 2008, where the application of different algorithms or proprietary solutions are proposed. This article is a response to the search for optimal shapes of slender mechanical systems subjected to a conservative load.

\section{PHYSICAL MODEL}

Figure 1 shows the physical model of the considered column. In the selected case of implemented specific load, the direction of the external force $P$ passes through the point $O_{1}$ (a centre of a curvature of load-receiving head) and constant point $O$ (a centre of a 
curvature of loading head). The column was fixed rigidly on one side $\left(x_{1}=0\right)$ and connected at a free end $\left(x_{n}=l\right)$ to the load-receiving head.

Modelling of the system's variable cross-section takes place by dividing the column into segments (indexed $i=1 . . n)$ of a circular cross-section, mass per unit length $\left(\rho A_{i}\right)$ and flexural stiffness $\left(E J_{i}\right)$, described by the length $l$ and diameter $d_{i}$ as well as transverse displacement $\mathrm{W}_{i}\left(x_{i}, t\right)$. Optimization of the shape comes to the selection of the diameters of individual segments, at which the maximum critical load value is a function of several variables can be obtained:

$$
P_{\max }=f\left(d_{1}, d_{2}, \ldots, d_{n}, \frac{L}{n}\right) .
$$
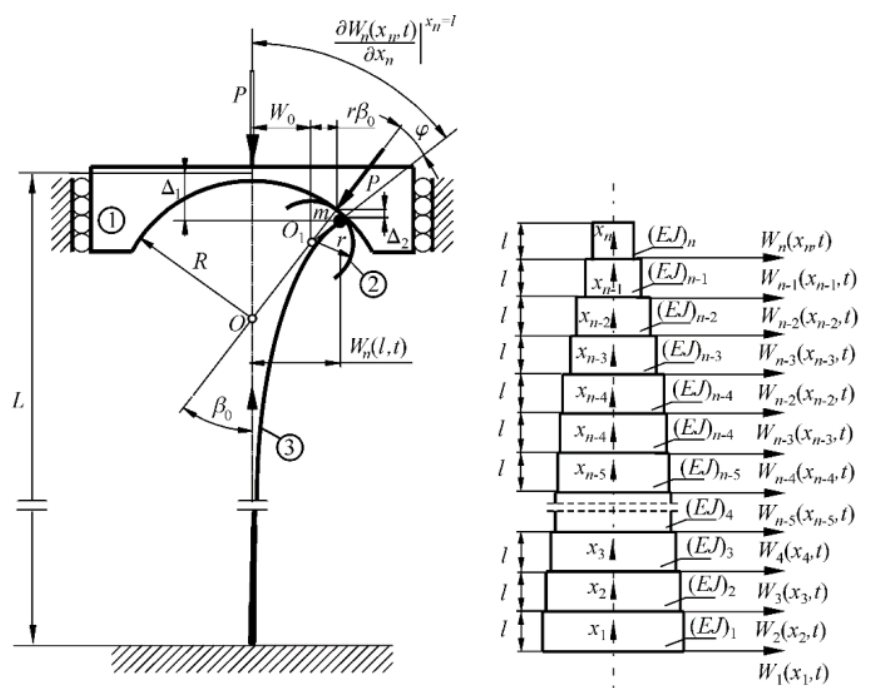

Fig. 1. The physical model of as column under the generalized load with a force directed towards the positive pole. Column division into segments

The value of the critical force $P_{k r}$ of the optimized columns was referenced to the stiffness per bending $(E J)_{p}$ constant along the length $L$ of a the comparative column:

$$
\lambda_{o c}=\frac{P_{k r} L^{2}}{(E J)_{p}} \text {. }
$$

The following assumptions were made: constant total length $L$, constant volume $v$, constant value of modulus of elasticity $E$ and density of material $\rho$ of individual segments of optimized columns and corresponding comparative (prismatic) columns:

$$
L=n l, \quad v=\sum_{i=1}^{n} v_{i}, R_{o}^{*}=\frac{R}{L}, \Delta r=\frac{R-r}{L} .
$$

Indications of considered columns:

- $\mathrm{CO}\left(R_{o}^{*}, \Delta r\right)$ - optimized column with a stepped flexural stiffness with the parameter of the loading head $R_{o}^{*}$ and the parameter of the load-receiving head $\Delta r$,

- CP $\left(R_{o}^{*}, \Delta r\right)$-column with a constant flexural stiffness (comparative system) with the parameter of the loading head $R_{o}^{*}$ and the parameter of the load-receiving head $\Delta r$.

\section{FORMULATION AND SOLUTION OF A BOUNDARY PROBLEM}

Determination of the differential equations of motion and boundary conditions of the analyzed system was carried out using the Hamilton principle (see Tomski and Szmidla, 2007): 


$$
\delta \int_{t_{1}}^{t_{2}}\left(T-\sum_{\xi=1}^{3} V_{\xi}\right) d t=0
$$

where: $\delta$ - variation operator, $t$ - time.

The kinetic energy $T$ of the system under consideration is the sum of the kinetic energy of the column and the kinetic energy of a concentrated mass $m$ :

$$
T=\sum_{i=1}^{n} \frac{\left(\rho A_{i}\right)}{2} \int_{0}^{l}\left[\frac{\partial W_{i}\left(x_{i}, t\right)}{\partial t}\right]^{2} d x_{i}+\frac{m}{2}\left[\frac{\partial W_{n}(l, t)}{\partial t}\right]^{2} .
$$

while $A_{i}$ is a cross-section of $i$ - th segment of the optimized column.

The potential energy consists of the bending elasticity energy and the energy coming from the external load:

$$
\begin{gathered}
V=\sum_{i=1}^{n} \frac{\left(E J_{i}\right)}{2} \int_{0}^{l}\left[\frac{\partial^{2} W_{i}\left(x_{i}, t\right)}{\partial x_{i}^{2}}\right]^{2} d x_{i}-\frac{P}{2} \sum_{i=1}^{n} \int_{0}^{l}\left[\frac{\partial W_{i}\left(x_{i}, t\right)}{\partial x_{i}}\right]^{2} d x_{i}+ \\
+P \frac{r}{2}\left[\left[\left.\frac{\partial W_{n}\left(x_{n}, t\right)}{\left.\partial x_{n}\right)}\right|^{x_{n}=l}\right]^{2}-\beta_{0}^{2}\right]+\frac{1}{2} P \beta_{0}\left[W_{0}+r \beta_{0}\right], \\
\text { where: } \phi=\frac{W_{0}}{R-r}=\frac{\left.R \frac{\partial W_{n}\left(x_{n}, t\right)}{\partial x_{n}}\right|^{x_{n}=l}-W_{n}(l, t)}{R-r}, \quad \beta_{0}=\frac{W_{n}(l, t)-\left.r \frac{\partial W_{n}\left(x_{n}, t\right)}{\partial x_{n}}\right|^{x_{n}=l}}{R-r} .
\end{gathered}
$$

The geometrical boundary conditions, including the conditions of continuity have the form:

$$
\begin{gathered}
W_{1}(0, t)=\left.\frac{\partial W_{1}\left(x_{1}, t\right)}{\partial x_{1}}\right|_{x_{1}=0}=0, \\
W_{\zeta}(l, t)=W_{\zeta+1}(0, t),\left.\frac{\partial W_{\zeta}\left(x_{\zeta}, t\right)}{\partial x_{\zeta}}\right|^{x_{\zeta}=l}=\left.\frac{\partial W_{\zeta+1}\left(x_{\zeta+1}, t\right)}{\partial x_{\zeta+1}}\right|_{x_{\zeta+1}=0},
\end{gathered}
$$

where: $\zeta=1 \ldots(n-1)$.

Taking into consideration the variation of the potential energy in the Hamilton principle (4), after using the boundary conditions (7) and performing the algebraic transformations, the equations of motion of particular segment:

$$
\left(E J_{i}\right) \frac{\partial^{4} W_{i}\left(x_{i}, t\right)}{\partial x_{i}^{4}}+P \frac{\partial^{2} W_{i}\left(x_{i}, t\right)}{\partial x_{i}^{2}}+\left(\rho A_{i}\right) \frac{\partial^{2} W_{i}\left(x_{i}, t\right)}{\partial t^{2}}=0, \quad i=1 \ldots n,
$$

and natural boundary conditions:

$$
\begin{gathered}
\left.\frac{\partial^{2} W_{\zeta}\left(x_{\zeta}, t\right)}{\partial x_{\zeta}^{2}}\right|^{x_{\zeta}=l}=\left.\chi_{\zeta+1} \frac{\partial^{2} W_{\zeta+1}\left(x_{\zeta+1}, t\right)}{\partial x_{x_{\zeta+1}}^{2}}\right|_{x_{\zeta+1}=0}, \\
\left.\frac{\partial^{3} W_{\zeta}\left(x_{\zeta}, t\right)}{\partial x_{\zeta}^{3}}\right|^{x_{\zeta}=l}=\left.\chi_{\zeta+1} \frac{\partial^{3} W_{\zeta+1}\left(x_{\zeta+1}, t\right)}{\partial x_{x_{\zeta+1}^{3}}^{3}}\right|_{x_{\zeta+1}=0}, \\
\left.\frac{\partial^{2} W_{n}\left(x_{n}, t\right)}{\partial x_{n}^{2}}\right|^{x_{n}=l}+k_{n}^{2}\left[\left.\rho_{1} \frac{\partial W_{n}\left(x_{n}, t\right)}{\partial x_{n}}\right|^{x_{n}=l}+v_{1} W_{n}(l, t)\right]=0,
\end{gathered}
$$




$$
\left.\frac{\partial^{3} W_{n}\left(x_{n}, t\right)}{\partial x_{n}^{3}}\right|^{x_{n}=l}+k_{n}^{2}\left[\left.\mu_{1} \frac{\partial W_{n}\left(x_{n}, t\right)}{\partial x_{n}}\right|^{x_{n}=l}+\gamma_{1} W_{n}(l, t)\right]-\frac{m}{\left(E J_{n}\right)} \frac{\partial^{2} W_{n}\left(x_{n}, t\right)}{\partial t^{2}}=0 .
$$

were obtained, where: $\rho_{1}, v_{1}, \mu_{1}, \gamma_{1}$ are coefficients dependent on the geometry of the loading stucture (see Tomski and Szmidla, 2007), $k_{n}^{2}=P /\left(E J_{n}\right), \quad \chi_{\zeta+1}=\left(E J_{\zeta+1}\right) /\left(E J_{\zeta}\right)$.

The general solutions of equations (8) have been described by the function (10) using the vibration criterion:

$$
y_{i}\left(x_{i}\right)=C_{1 i} \cosh \left(\alpha_{i} x_{i}\right)+C_{2 i} \cos \left(\beta_{i} x_{i}\right)+C_{3 i} \sinh \left(\alpha_{i} x_{i}\right)+C_{4 i} \sin \left(\beta_{i} x_{i}\right) .
$$

Taking into account solutions in boundary conditions enables determination of the vibrations frequency and the critical force of the analyzed system.

\section{SIMULATED ANNEALING}

The simulated annealing method is a heuristic algorithm belonging to the class of nondeterministic algorithms. This method is a modification of a "hill climbing" algorithm The operation of the algorithm requires defining four parameters: the initial representation of the solution, the generator of random changes in the solution (neighbourhood function), the evaluation function (cost) and the " annealing schedule ". The additional parameter $\Theta$ called "temperature" is not directly related to variables that are subject to optimization, but only controls the operation of the algorithm. The value of the parameter $\Theta$ affects only the probability of passing from one point in the search space to another (see Michalewicz and Fogel, 2006) and is selected in a manner depending on the given optimization issue.

The core of the algorithm is a procedure called Metropolis (see Michalewicz and Fogel, 2006) which is used to simulate the annealing process at a given "temperature" $\Theta$. In the Metropolis procedure, the number of iterations specified by parameter $M$ is performed at the same value of parameter $\Theta$. Then "temperature" is reduced in accordance with the adopted "cooling scheme". The number of $M_{\max }$ iterations in subsequent initiation of the Metropolis procedure is increased by a certain value of $\Delta M$. In the modified simulated annealing method presented in this work, apart from changing the values of $\Theta$ and $M$, the performance of the neighbourhood function was changed along with the change of "temperature" parameter. Another implemented modification of the simulated annealing algorithm is a change of the number of segments $n$ made together with the change in the values of the mentioned parameters. Detailed information on the modifications applied, including the block diagram of the algorithm is described in the publication of Szmidla, 2009.

\section{RESULTS OF NUMERICAL COMPUTATIONS}

This chapter presents selected results of numerical calculations regarding to the kinetic criterion of a stability loss for selected geometrical parameters of loading structure. The full range of the results of numerical analyzes was presented in the publication of Szmidla, 2009. Taking into account the solution of the boundary issue (10) numerical calculations concerning the value of natural frequency $\omega$ of the column $\operatorname{CO}\left(R_{o}^{*} j, \Delta r k\right)$ were carried out and the maximum values of the critical load $P_{k r}$ of the column were determined. The work was limited to determining the character of the changes of the first two natural frequencies in the dimensionless form $\Omega_{o 1}, \Omega_{o 2}$ as a function of 
dimensionless parameter of external load $\lambda_{o}$ for selected values of loading structure parameters:

$$
\lambda_{o}=\frac{P L^{2}}{(E J)_{p}}, \Omega_{o}=\frac{(\rho A)_{p} \omega^{2} L^{4}}{(E J)_{p}} .
$$

The calculations were made by dividing the columns up to $n=128$ segments

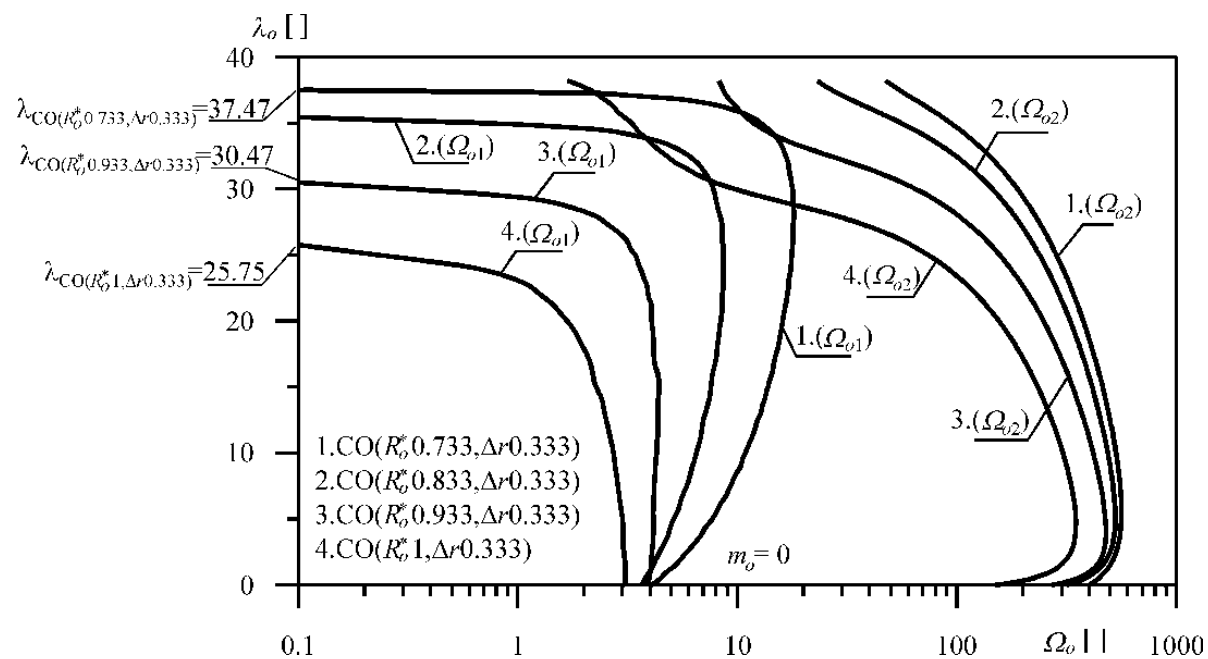

Fig. 2. Curves on the plane: external load parameter $\lambda_{o}-$ the natural frequency parameter $\Omega_{o}$ (system $\mathrm{CO}\left(R_{o}^{*} j, \Delta r \quad 0.333\right)$ )

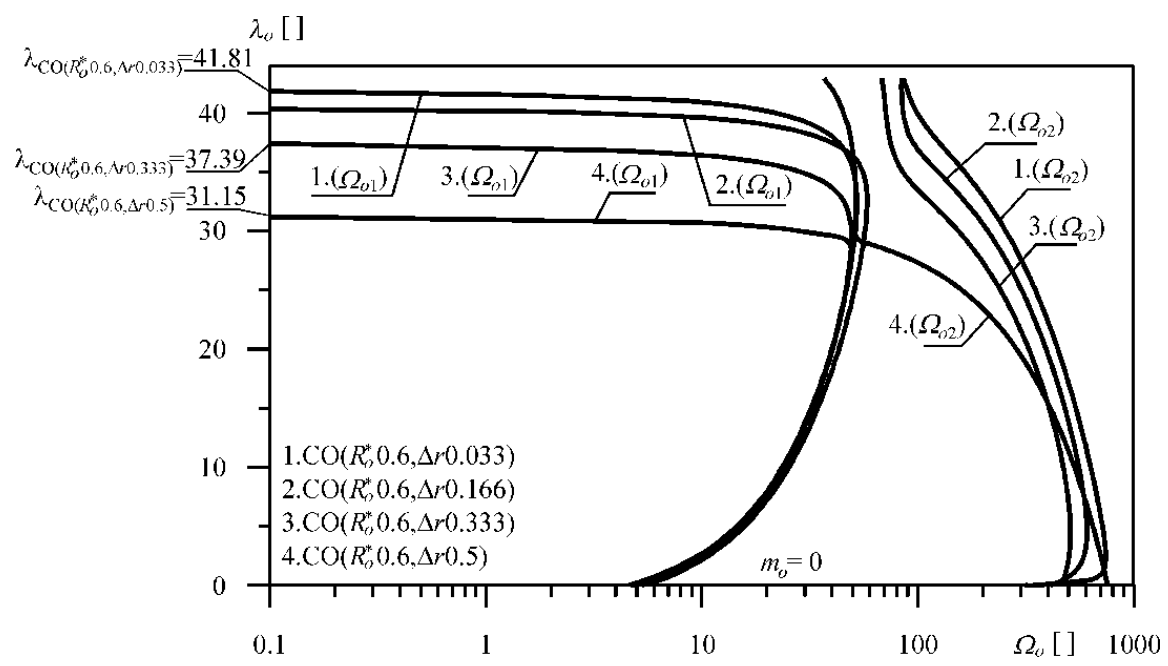

Fig. 3. Curves on the plane: external load parameter $\lambda_{o}$ - the natural frequency parameter $\Omega_{o}$ (system $\mathrm{CO}\left(R_{o}^{*} 0.6, \Delta r k\right)$ )

Figure 2 presents an influence of variable coefficient $R_{o}^{*}$ on the course of eigenvalues for selected value of parameter $\Delta r$. An influence of changes in the geometry of loading head $\Delta r$ at a constant value of radius $R$ is represented by the curves of natural frequency in Figure 3. Based on the applied kinetic criterion of stability, critical loads of the analyzed systems corresponding to the zero value of the basic vibration frequency were determined. Depending on the value of the geometric parameters of the heads, the slopes of the curves of the basic natural frequency (Figs. 2-3) are negative, positive or equal to zero. This allows for the inclusion of optimized and comparative columns under the specific load to one of two types of systems: divergent or divergent pseudo-flutter type. 

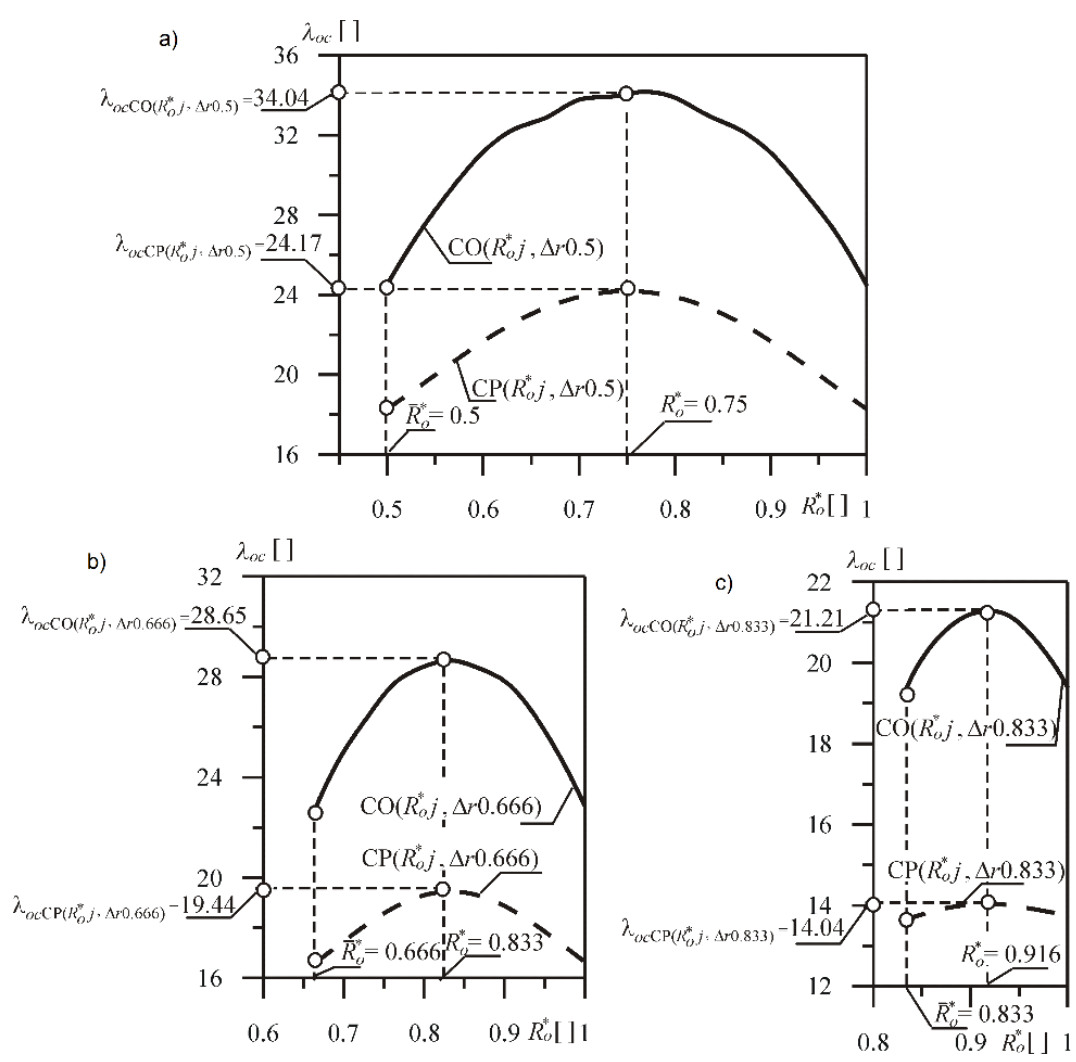

Fig. $4 \mathrm{a} \div \mathrm{c}$. Change of the critical load parameter $\lambda_{o c}$ as a function of the value of parameter $R_{o}^{*}$ of the systems: a) $\mathrm{CO}\left(R_{o}^{*} j, \Delta r \quad 0.5\right), \mathrm{CP}\left(R_{o}^{*} j, \Delta r 0.5\right)$, b) $\mathrm{CO}\left(R_{o}^{*} j, \Delta r 0.666\right), \mathrm{CP}\left(R_{o}^{*} j, \Delta r 0.666\right)$, c) $\mathrm{CO}\left(R_{o}^{*} j, \Delta r\right.$ 0.833), $\mathrm{CP}\left(R_{o}^{*} j, \Delta r\right.$ 0.833).

Figures $4 a \div c$ show the scope of changes of the parameter of critical load as a function of the parameters of the loading and receiving heads. The results of numerical calculations were presented for the optimized shape systems (continuous lines) and corresponding comparative columns (dashed lines).

For the considered values of the radius $R$ of loading head, each of the curves of critical load changes was characterized by the occurrence of the maximum critical value of the load parameter $\lambda_{o c}$. In the case of comparative columns, the extreme value is denoted by the parameters $R_{o}^{*}, \Delta r$ satisfying the relation: $2 R_{o}^{*}-\Delta r=1$.

The percentage increase in the critical load $\delta_{o}$ of the optimized columns with variable flexural stiffness in comparison to this load obtained for prismatic column is shown in Figures $5 \mathrm{a} \div \mathrm{c}$, where:

$$
\delta_{o}=\frac{\lambda_{o c \operatorname{CO}\left(R_{o}^{*} j, \Delta r\right)}-\lambda_{o c \mathrm{CP}\left(R_{o}^{*} j, \Delta r\right)}}{\lambda_{o c \mathrm{CP}\left(R_{o}^{*} j, \Delta r\right)}} 100 \%
$$

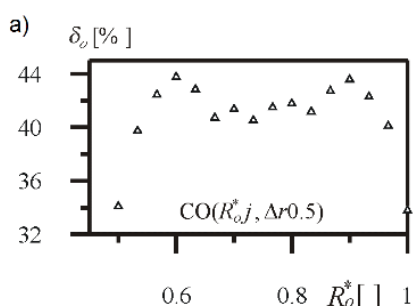

b) $\delta_{o}[\%]$
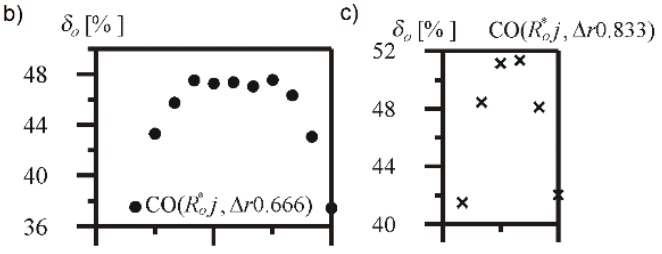

$0.6 \quad 0.8 R_{o}^{*}[] \quad 1$

$0.8 R_{o}^{*}[] 1$

Fig. $5 \mathrm{a} \div \mathrm{c}$. The percentage increase in the critical load $\delta_{o}$ in relation to the parameter $R_{o}^{*}$ :

a) $\mathrm{CO}\left(R_{o}^{*} j, \Delta r\right.$ 0.5), $\left.\mathrm{CP}\left(R_{o}^{*} j, \Delta r 0.5\right), \mathrm{b}\right) \mathrm{CO}\left(R_{o}^{*} j, \Delta r 0.666\right), \mathrm{CP}\left(R_{o}^{*} j, \Delta r 0.666\right)$,

c) $\mathrm{CO}\left(R_{o}^{*} j, \Delta r\right.$ 0.833), $\mathrm{CP}\left(R_{o}^{*} j, \Delta r \quad 0.833\right)$. 


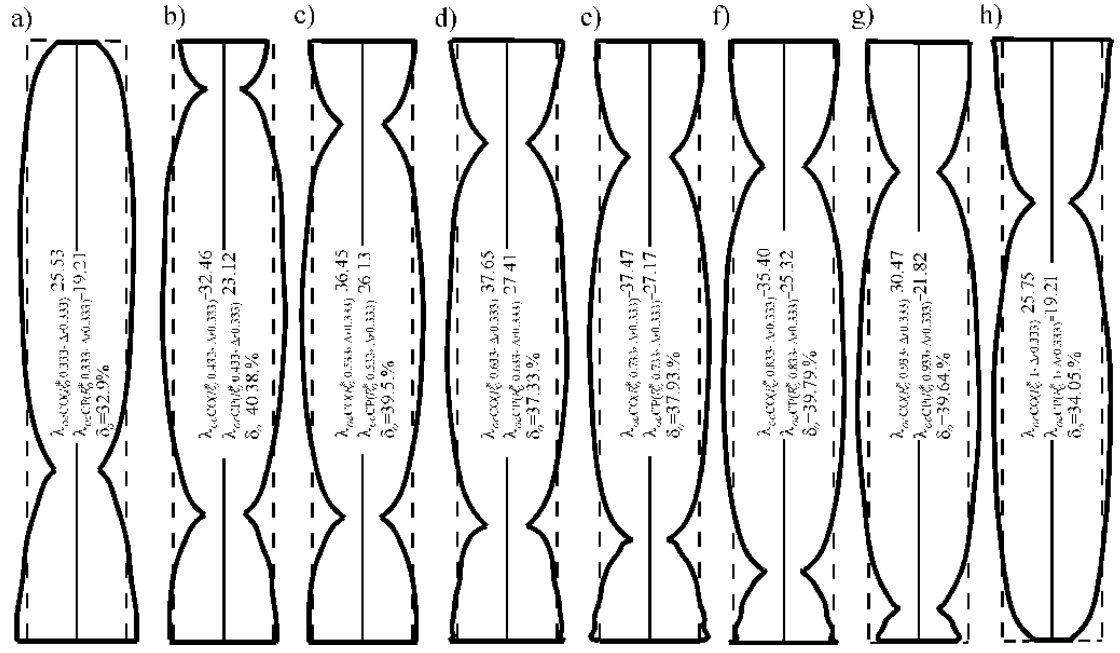

Fig. $6 \mathrm{a} \div \mathrm{h}$. Shapes of the column $\mathrm{CO}\left(R_{o}^{*} j, \Delta r\right.$ 0.333) for different values of parameter $R_{o}^{*}$ : a) $R_{o}^{*}=0.333$, b) $R_{o}^{*}=0.433$, c) $R_{o}^{*}=0.533$,

d) $R_{o}^{*}=0.633$, e) $R_{o}^{*}=0.733$, f) $\left.\left.R_{o}^{*}=0.833, \mathrm{~g}\right) R_{o}^{*}=0.933, \mathrm{~h}\right) R_{o}^{*}=1.0$

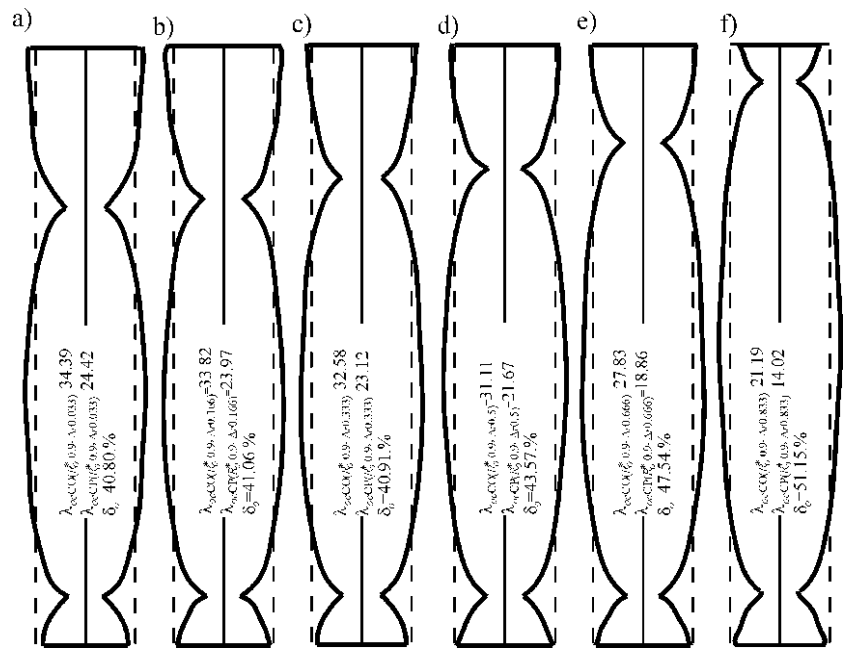

Fig. 7a $\div$ f. Shapes of column $\operatorname{CO}\left(R_{o}^{*} 0.9, \Delta r \mathrm{k}\right)$ for variable value of parameter $\Delta r$ : a) $\Delta r=0.033$, b) $\Delta r=0.166$, c) $\Delta r=0.333$, d) $\Delta r=0.5$, e) $\Delta r=0.666$, f) $\Delta r=0.833$.

Taking into account the division of the columns into $n=128$ segments, an increase in the critical load was achieved by a maximum of $51.74 \%$ in the case of the column $\mathrm{CO}\left(R_{o}^{*} j, \Delta r\right.$ 0.833) (fig. 5c).

Figures $6 \div 7$ show the shapes of the optimized columns models for selected parameters of loading. As a result of numerical calculations according to the optimization problem, a "stepped" shapes of systems were obtained. Due to the significant number of segments with respect to the total length $L$ of the columns, the actual shapes were approximated and drawn as continuous. The shapes of prismatic (comparative) columns are marked with dashed lines. For each of the shapes shown, the value of the critical force of the optimized and corresponding prismatic column as well as the percentage increase of the critical load parameter were given.

\section{CONCLUSION}

The aim of the work was a numerical analysis and shape optimization of a slender system subjected to a generalized load with a force directed to the positive pole. The 
issues of stability and free vibrations were formulated on the basis of the Hamilton's principle. In the scope of optimization problem, the properties of the simulated annealing algorithm were used. As part of the research on the dynamic properties of the columns, the change in the natural frequency of vibrations as a function of the external load was determined. On the basis of the obtained characteristic curves, the system under study was classified as a divergent or divergent pseudoflutter type of system.

As a result of the conducted research, the maximal increase of critical load of the system was obtained at the level of $51.74 \%$ in comparison with the comparative system of the same volume. The determined shapes of nonprismatic columns are characterized by the occurrence of narrowings, the position of which depends on the direction of the external load.

\section{ACKNOWLEDGEMENTS}

The study has been carried out within the framework of project BS/PB-1-101-3021/17 realized at Częstochowa University of Technology.

\section{REFERENCES}

Bochenek, B., Tajs - Zielińska, K., 2008. Optimization of beams and columns using cellular automata, Czasopismo Techniczne. Mechanika, 5 (4-M), 19-30.

Drazumeric ,R., Kosel, F., 2012. Shape optimisation of beam due to lateral buckling problem, International Journal of Non-Linear Mechanics, 47, 65-74.

Krużelecki, J., Barski, M., 2008. Optimization of stability of columns with clampedclampedguided ends, Czasopismo Techniczne. Mechanika, 5 (4-M), 71-82.

Michalewicz, Z., Fogel, D.B., 2006. Jak to rozwiązać, czyli nowoczesna heurystyka, Wydawnictwa Naukowo-Techniczne, Warsaw, Poland.

Nikolic, A., Salinic, S., 2017. Buckling analysis of non-prismatic columns: A rigid multibody approach, Engineering Structures, 143, 511-521.

Ruta, P., Szybiński, J., 2015. Nonlinear analysis of nonprismatic Timoshenko beam for different geometric nonlinearity models, International Journal of Mechanical Sciences, 101-102, 349-362.

Szmidla, J., 2009. Drgania swobodne I stateczność układów smukłych poddanych obciążeniu swoistemu, Wydawnictwo Politechniki Częstochowskiej, Częstochowa, Poland.

Szmidla, J., Jurczyńska, A., 2015. The tapered column shape optimization in a plane perpendicular to the buckling plane subjected to the positive pole, Machine Dynamics Research, 39(2), 33-44.

Szmidla, J., Wawszczak, A., 2008. Optymalizacja kształtu kolumn realizujących wybrane przypadki obciążenia Eulera za pomocą zmodyfikowanego algorytmu symulowanego wyżarzania, XIII Sympozjum Dynamiki Konstrukcji DYNKON, Rzeszów, Poland, 333-344.

Tomski, L., Szmidla, J, 2007. Free vibrations and stability of discrete systems subjected to the specific load, Journal of Theoretical and Applied Mechanics, 45 (4), 873-892

Tsiatas, G. C., 2010. Nonlinear analysis of non-uniform beams on nonlinear elastic foundation, Acta Mechanica, 209, 141-152. 